Ana Thereza Meireles Araújo ${ }^{1}$ José Edson Oliveira Araújo Filho ${ }^{1}$

\title{
TRANSPLANTES HEMATOLÓGICOS E SELEÇÃO GENÉTICA EM PROJETOS PARENTAIS
}

Hematological transplantations and genetic selection in assisted parenthood projects

${ }^{1}$ Universidade Federal da Bahia. Salvador/BA, Brasil.

Correspondência: Ana Thereza Meireles Araújo. E-mail: anatherezameirelles@gmail.com

Recebido: 17/09/2018. Revisado: 11/04/2019. Aprovado: 13/05/2019. 


\section{RESUMO}

$\mathrm{O}$ artigo destina-se à análise de projetos parentais assistidos voltados à reprodução de indivíduo compatível com receptor que possui doença hematológica com indicação de transplante. A pesquisa foi construída a partir de uma análise médico-jurídica, com base na constatação da necessidade de esclarecimentos que pertencem às duas esferas da ciência. Como objetivo, buscou-se identificar se a reprodução programada de alguém para benefício de outrem avilta os direitos da pessoa, expressos no sentido constitucional de dignidade humana. Para isso, teve-se como pressuposto relevante o acesso a conhecimentos de natureza médica, que envolveram a compreensão dos indicadores de transplantes e da seleção genética conduzida pelo argumento terapêutico, para, posteriormente, adentrar a avaliação das motivações relacionadas à realização do procedimento assistido de reprodução. A pesquisa tem natureza teórica, adotando o método analítico-discursivo.

\section{Palavras-Chave:}

Bebê Doador; Bioética; Seleção Genética; Transplantes Hematológicos.

\section{ABSTRACT}

This article is intended to analyze assisted parenthood projects aimed at the reproduction of an individual who is compatible with a recipient affected by hematological disease with indication for transplantation. This research was constructed from a medical and legal analysis, based on the need of clarifications belonging to both spheres of Science. The aim is to understand whether the decision of seeking programed birth of someone for the benefit of someone else degrades the rights of the human person, expressed by the constitutional concept of human dignity. For this, the access to medical knowledge was considered as relevant assumption, involving the understanding of transplantation indicators, genetic selection conducted by the therapeutic argument, and the subsequent evaluation of the motivations leading to assisted reproduction. The research is theoretical, adopting the analytical-discursive method.

\section{Keywords:}

Baby Donor; Bioethics; Genetic Selection; Hematological Transplantations. 


\section{Introdução}

A área da genética aponta para uma série de imbricadas possibilidades que se misturam num contexto de domínio técnico difícil de ser compreendido por outros segmentos científicos. É certo que a possibilidade de manipular geneticamente o ser humano representa o desvelamento de um problema ético sem precedentes, na medida em que se reconheça como pressuposto que a medicina genética tem se tornado um caminho terapêutico expressivo.

A seleção genética, aqui enfatizada, oferece a possibilidade de escolha de embriões capazes de gerar pessoas geneticamente compatíveis com outros seres humanos (os irmãos) que sofrem de doença genética grave, originada por comprometimentos celulares sanguíneos e revelada por meio de diagnósticos como leucemias, anemias de diversas ordens e talassemia, entre outras. Essa possibilidade tem gerado questionamentos em torno da possível instrumentalização de um ser humano, demandando uma reflexão sobre os motivos que justificam a realização de um projeto parental com tal finalidade versus a condição atribuída ao indivíduo originado de um embrião selecionado.

Este artigo apresenta estudo que contempla a avaliação da incidência das indicações de transplante, majoritariamente relacionadas a doenças de natureza hematológica. Para a adequada construção de um discurso ético-jurídico, tornou-se indispensável a investigação dos argumentos médicos que pudessem sustentar a realização de um projeto parental com tais características.

Acrescente-se ao problema o fato de a seleção genética diagnóstica não servir apenas à finalidade terapêutica, como também agregar um espectro amplo de possibilidades capazes de fundamentar a concretização de escolhas neoeugênicas, ou seja, pautadas em características específicas que podem ter motivações de cunho aperfeiçoador, fulcradas em ideias de melhoramento ou superioridade genética.

A seleção genética ora analisada contempla a possibilidade de uma pessoa ser gerada de maneira assistida com o propósito de beneficiar terapeuticamente o irmão. A relevância ética, social e jurídica do tema justifica a proposta em estudo.

Assim, o objetivo desta pesquisa é justamente identificar se a conduta que almeja a seleção de embriões voltada para reprodução de um indivíduo potencialmente doador de outro avilta os direitos do primeiro. Busca-se avaliar os fundamentos concernentes à discussão em prol de apontar a medida de legitmidade e legalidade do projeto parental programado para fins de doação.

A pesquisa tem, ainda, como propósito relevante o descortinamento dos fundamentos médicos que indicam a possibilidade de transplante por meio da realização de um projeto parental programado e motivado pela garantia da compatibilidade entre o doador e o receptor. Urge esclarecer que nem todas as possíveis indicações de transplante por meio de um projeto parental assistido estão contingenciadas pela 
natureza hematológica; no entanto, tendo em vista o número expressivo de doenças relacionadas ao sangue, o trabalho tem como foco a análise a partir desta perspectiva.

A pesquisa tem natureza teórica e adota uma abordagem analítico-discursiva, na medida em que parte dos fundamentos da doutrina, tanto da medicina quanto do Direito, da legislação vigente e das informações veiculadas sobre projetos assistidos já realizados, para construção de um entendimento adequado a respeito da seleção embrionária.

\section{Aportes médicos em hematologia}

O primeiro registro científico da realização de um transplante de células-tronco hematopoiéticas (relacionadas, portanto, ao sangue) data de 1939. Entretanto, somente após alguns anos, entre 1975 e 1978, obteve-se o conhecimento necessário para ampliação e inclusão de tal possibilidade terapêutica no contexto do tratamento de alguns tipos de leucemia ${ }^{1}$.

Com o avanço substancial dos estudos em genética aplicada à clínica, dos biomarcadores e do conhecimento da fisiopatologia das doenças, principalmente hematológicas, o transplante de células-tronco hematopoiéticas ganhou status de opção terapêutica para uma série de doenças ${ }^{2}$. Registre-se que esse avanço pressupôs a realização de inúmeros estudos científicos, assim como aconteceu em toda a cadeia de possibilidades transplantárias hoje conhecidas pela medicina.

Deve-se ter ciência de que, mesmo com a crescente divulgação e amplificação das indicações terapêuticas dos transplantes, o acesso esse tipo de procedimento é relatado como restrito a grandes centros financeiros e a locais onde existam iniciativas governamentais que auxiliem a construção de serviços especializados ${ }^{3}$. Há considerável e necessária demanda tecnológica para a implantação do procedimento e, de alguma forma, também é necessária a articulação entre sociedade e governo para a construção de serviços médicos que abarquem a necessidade da população. Os avanços na área do transplante apontam para a necessidade de atuação efetiva do Estado na garantia do suporte necessário para que os procedimentos aconteçam. Assim, seja para qualquer órgão do corpo humano, falar de transplante é sempre falar de algo que demanda um esforço especial em diversos planos, como a formação dos profissionais capacitados, o suporte ambiental e técnico de hospitais e clínicas e o aspecto econômico, já que são necessários investimentos significativos para o fornecimento adequado do serviço.

1INSTITUTO NACIONAL DE CÂNCER - INCA. Informações sobre transplante de células hematopoiéticas. Disponível em: http://www2.inca.gov.br/wps/wcm/connect/orientacoes/site/home/informacoes_sobre_ doacao_de_medula_ossea. Acesso em: 21 maio 2018.

${ }^{2}$ GRATWOHL, Alois et al. Worldwide Network of Blood and Marrow Transplantation. Hematopoietic stem cell transplantation: a global perspective. Journal of the American Medical Association, v. 303, n. 16, p. 16171624, Apr. 2010. https://doi.org/10.1001/jama.2010.491.

3/d. Ibid. 
Pode-se realizar o transplante de células-tronco primordiais do sangue por meio da coleta de células em fontes distintas, oriundas da medula óssea, do sangue periférico ou do cordão umbilical ${ }^{4}$. O médico do paciente determina a fonte apropriada, baseado na doença e no estado de saúde do paciente. Assim, todos os doadores são cuidadosamente selecionados para prevenir quaisquer doenças transmissíveis e detectar outros problemas médicos que possam impedi-los de doar células-tronco ${ }^{5}$. Apesar dos recentes avanços nas técnicas de coleta e uso do sangue periférico e de cordão umbilical como novas alternativas, deve-se ainda considerar que a medula óssea é a primordial fonte de coleta ${ }^{6}$.

A indicação do transplante de medula óssea está relacionada principalmente a tratamento de doenças que comprometem o funcionamento da medula, como doenças hematológicas e onco-hematológicas, imunodeficiências, doenças genéticas hereditárias, alguns tumores sólidos e doenças autoimunes ${ }^{7}$. O primeiro transplante bem-sucedido de medula óssea foi realizado em 1968 em uma criança com imunodeficiência combinada, na University of Minnesota, Estados Unidos. Em março de 1969, em Seattle, também nos Estados Unidos, o transplante foi realizado com a utilização de radioterapia, tendo em vista ser o paciente portador de leucemia. No Brasil, os transplantes passaram a ser realizados em 1979 na Universidade Federal do Paraná; em 1983, foi criada uma unidade de transplante no Instituto Nacional do Câncer (Inca), no Rio de Janeiro, e, em 1988, o transplante de medula óssea foi implantado na Faculdade de Medicina da Universidade de São Paulo .

O transplante de células-tronco hematopoiéticas não é o tratamento de primeira linha na maioria dos pacientes, entretanto, em alguns contextos clínicos, configura-se como única possibilidade de cura9 ${ }^{9}$. Isso porque é sabido na medicina que outras opções terapêuticas devem anteceder o transplante. A medicina aponta para um conjunto de indicações das doenças nas quais o transplante de células-tronco primordiais do sangue configura-se possibilidade terapêutica ${ }^{10}$, seja na modalidade alogênica ou heteróloga (com sangue de doador), seja na modalidade autóloga (com o uso do sangue do próprio indivíduo a ser transplantado). Acrescente-se, ainda, a

\footnotetext{
${ }^{4}$ HOFFBRAND, A. Victor; MOSS, Paul A. H. Fundamentos em hematologia. 6. ed. Porto Alegre: Artmed, 2013. ${ }^{5}$ LEUKEMIA \& LYMPHOMA SOCIETY. Blood and marrow stem cell transplantation. Revised 2018. Tampa, FL: Sanofi Genzyme, 2018. p. 23. https://www.lls.org/sites/default/files/file_assets/PS40_ BloodMarrow_2018.pdf.

${ }^{6}$ COPELAN, Edward A. Hematopoietic stem-cell transplantation. N Engl J Med., n. 354, p. 1813-1826, 2006. ${ }^{7}$ VOLTARELLI, Júlio C.; PASQUINI, Ricardo; ORTEGA, Euza T. T. Transplante de células-tronco hematopoéticas. São Paulo: Atheneu; 2009.

${ }^{8}$ GARRAFA, Volnei; CORGOZINHO, Marcelo; GOMES, Jacqueline. Transplantes de medula óssea no Brasil: dimensão bioética. Rev. latinoam. bioetica, Bogotá, v. 12, n. 1, p. 36, 2012, ene./jun. 2012. Disponível em: http://www.scielo.org.co/pdf/rlb/v12n1/v12n1a04.pdf.

${ }^{9}$ COPELAN, Edward A. op. cit.; HOFFBRAND, A. Victor; MOSS, Paul A. H. op. cit.; INSTITUTO NACIONAL DE CÂNCER - INCA. Informações sobre transplante de células hematopoiéticas, cit.

${ }^{10}$ ld. Ibid.
} 
modalidade singênica, em que o transplante é feito entre irmãos gêmeos e, portanto, com padrão de compatibilidade ideal ${ }^{11}$.

Em sua proposta inicial, o transplante de células-tronco hematopoiéticas foi usado como última medida em pacientes que não respondiam de fato ao tratamento convencional existente, porém "os avanços nos cuidados de suporte e a compreensão ampla do método, que estabeleu suas principais indicações, bem como as suas limitações e complicações, tornaram esse procedimento uma estratégia terapêutica cada vez mais utilizada para diversas enfermidades"12. A principal limitação ao transplante é a compatibilidade entre doador e receptor.

Doenças como leucemias agudas e crônicas, linfomas, mieloma múltiplo, anemia aplásica, anemia de Fanconi, anemia falciforme, talassemia major, hemoglobinúria paroxística noturna, mielofibrose primária e aplasia eritroide podem agregar indicações de transplantes alogênicos. $\mathrm{O}$ transplante autólogo pode compreender indicações de doenças como linfomas de Hodgkin e não Hodgkin, alguns casos de mieloma múltiplo, leucemia mieloide aguda, doenças autoimunes, neuroblastoma, câncer de ovário e câncer de células germinativas ${ }^{13}$.

$\mathrm{Na}$ área em questão, deve-se ponderar que a evolução dos achados científicos aponta para conclusões cada vez mais importantes, e por vezes promissoras, quanto à escolha do tipo de transplante cabível para determinada patologia. É o caso, por exemplo, de recente estudo publicado no The New England Journal of Medicine, em que o transplante mieloablativo de células-tronco hematopoiéticas autólogas alcançou benefícios de longo prazo em pacientes com esclerodermia, incluindo melhor sobrevida, inexistência de eventos e diminuição da taxa de morte pós-transplante relacionada ao tratamento ${ }^{14}$. Inúmeros estudos publicados anualmente evidenciam a importância do transplante não somente para a hematologia, mas para a medicina de forma geral. Registra-se o fato de que o transplante de células-tronco hematopoiéticas pode ser uma possibilidade terapêutica para doenças hematológicas e não hematológicas, como miastenia gravis e artrite reumatoide ${ }^{15}$.

\footnotetext{
${ }^{11}$ INSTITUTO NACIONAL DE CÂNCER - INCA. Tópicos em transplante de células-tronco hematopoiéticas. Rio de Janeiro: Ministério da Saúde, INCA, 2012. p. 19. Disponível em: http://bvsms.saude.gov.br/bvs/ publicacoes/topicos_transplante_celtronco_hematopoeticas.pdf.

${ }^{12}$ Id. Ibid., p.19.

${ }^{13}$ COPELAN, Edward A. op. cit., p. 1815.

${ }^{14}$ SULLIVAN, Keith M. et al. Myeloablative autologous stem-cell transplantation for severe scleroderma. $N$ Engl J Med., n. 378, p. 35, Jan. 2018. https://doi.org/10.1056/NEJMoa1703327.

${ }^{15}$ ATTAL, Michel et al. Lenalidomide, Bortezomib, and Dexamethasone with Transplantation for Myeloma. N Engl J Med., n. 376, p.1311-320, Apr. 2017; BRYANT, A. et al. Myasthenia Gravis treated with autologous hematopoietic stem cell transplantation. Journal of the American Medical Association Neurology, v. 376, n. 6: p. 652-658, Jun. 2016. Disponível em: https://www.nejm.org/doi/pdf/10.1056/NEJMoa1611750?articleTools=true; MILANO, Filippo et al. Cord-blood transplantation in patients with minimal residual disease. N Engl J Med., n. 375, p. 944 953, 2016. https://doi.org/10.1056/NEJMoa1602074; SNOWDEN, J. A. et al. Autologous hemopoietic stem cell transplantation in severe rheumatoid arthritis: a report from the EBMT and ABMTR. J Rheumatol. , v. 31, n. 3, p. 482-488, Mar. 2004; PAl, Sung-Yun et al. Transplantation outcomes for severe combined immunodeficiency. $N$ Engl J Med., n. 371, p. 434-446, 2014. https://doi.org/10.1056/NEJMoa1401177.
} 
Por se tratar de procedimento com importante morbidade e mortalidade, sendo relacionado a danos renais, infecção, doença do enxerto versus hospedeiro, hemorragias e tumores malignos secundários, é importante frisar que a indicação clínica do transplante não deve, de forma alguma, ser realizada por critérios inflexíveis ${ }^{16}$. Na forma alogênica, o transplante de células-tronco hematopoiéticas perpassa pela aferição de compatibilidade entre doador e receptor; se inexistente a compatibilidade entre os indivíduos envolvidos no transplante, haverá rejeição ao enxerto. Essa avaliação parte da coleta de amostras de sangue dos sujeitos a fim de promover o mapeamento, o que inclui estudos genéticos e biomarcadores moleculares específicos, com vistas a identificar o grau de compatibilidade ${ }^{17}$. Antes de realizar o transplante de células-tronco hematopoiéticas, doses de quimioterápicos são usadas com o intuito de destruir as células doentes da medula óssea do receptor. Este receberá as células-tronco hematopoiéticas coletadas do doador (modalidade alogênica) ${ }^{18}$.

O Registro de Doadores de Medula Óssea (REDOME) existe no Brasil desde 1993 e, em 1999, foi vinculado ao Instituto Nacional do Câncer (Inca). São cerca de 14 milhões de doadores no mundo, sendo que 3,5 milhões deles estão localizados no Brasil, o que torna o registro brasileiro o terceiro maior do mundo, atrás apenas de Estados Unidos e Alemanha ${ }^{19}$.

A doação de células sanguíneas, em sua forma alogênica, pressupõe um doador compatível. A compatibilidade nem sempre é um elemento possível entre pessoas vivas, seja entre familiares ou entre os doadores registrados nos bancos de doação.

Dados científicos apontam para o fato de que "a maioria dos transplantes alogênicos realizados tem como doador os membros da família geneticamente idênticos para o HLA", que é o antígeno leucocitário humano. "A probabilidade de um indivíduo obter um irmão compatível é de $25 \%$, sendo influenciada pelo número de irmãos existentes em cada família. Para outros membros da família, a probabilidade é inferior a $5 \%{ }^{\prime 20}$.

Esse panorama é o lastro justificador que fomenta a busca pela possibilidade de executar um projeto parental assistido que permita a compatibilidade do doador a nascer com o receptor doente. Naturalmente que a cogitação de tal possibilidade já tem como pressuposto tentativas terapêuticas antecedentes fracassadas.

\footnotetext{
${ }^{16}$ HINGORANI, Sangeeta. Renal complications of hematopoietic-cell transplantation. N Engl J Med., v. 374, n. 23, p. 2256-2267, Jun. 2016. https://doi.org/10.1056/NEJMra1404711; HOFFBRAND, A. Victor; MOSS, Paul A. H. op. cit.

${ }^{17}$ HOFFBRAND, A. Victor; MOSS, Paul A. H. op. cit.; INSTITUTO NACIONAL DE CÂNCER - INCA. Informações sobre transplante de células hematopoiéticas, cit.

${ }^{18}$ Id. Ibid.

${ }^{19}$ INSTITUTO NACIONAL DE CÂNCER - INCA. Informações sobre transplante de células hematopoiéticas, cit.

${ }^{20}$ Id. Ibid., p. 19.
} 


\section{Fertilização in vitro e conduta diagnóstica}

As técnicas de reprodução humana assistida representam, hoje, um instrumento de consagração das novas formas familiares, na medida em que possibilitam a construção de projetos parentais calcados pela vontade de ter filhos, muitas vezes não viáveis por meio da procriação natural. O uso de tais técnicas agrega, considerando a perspectiva evolutiva, um plexo de novos questionamentos, tendo em vista envolver direitos das partes intentantes e bens jurídicos que precisam ser preservados.

Sem prejuízo da quantidade de técnicas usadas em procedimentos parentais assistidos, deve-se pensar que os métodos principais são a inseminação artificial e a fertilização in vitro. "A inseminação intrauterina (IIU) é uma técnica que consiste na deposição de amostra seminal, previamente tratada, no útero feminino, com o auxílio de um cateter de inseminação" ${ }^{21}$. $\mathrm{Na}$ inseminação artificial, há a coleta do sêmen para introdução na cavidade uterina, de maneira que a fecundação (junção dos gametas) só ocorrerá no corpo feminino, não havendo manipulação extracorpórea do zigoto ou embrião. Já a fertilização in vitro demanda a coleta de óvulos para associá-los aos espermatozoides em laboratório, o que faz com que a fecundação ocorra fora do corpo feminino, possibilitando o manuseio e a manipulação dos zigotos ou embriões concebidos extracorporeamente - ou seja, há uma totalidade de ações assistidas, de modo que todo o processo de formação embrionária seja acompanhado pelo especialista. Após a fecundação, alguns embriões formados podem apresentar problemas de desenvolvimento ou divisão celular inadequada, características que serão detectadas em biópsia embrionária ou diagnóstico pré-implantacional ${ }^{22}$.

Por meio da fertilização in vitro, tendo em vista o uso do diagnóstico pré-implantacional, é possível identificar se o embrião que originará novo indivíduo apresenta compatibilidade genética com o eventual receptor de um transplante. O diagnóstico genético pré-implantacional ou pré-implantatório usado na fertilização in vitro surgiu da conjunção dos avanços em duas áreas independentes: a medicina reprodutiva e a genética. É uma técnica usada para avaliar a condição do desenvolvimento embrionário antes da implantação. O procedimento é realizado antes da implantação do embrião no corpo da mulher e após a fertilização laboratorial. O diagnóstico genético em embriões pode ter finalidades distintas: a de ser um recurso terapêutico para impedir a implantação de conceptos com enfermidades graves ou para possibilitar a seleção para benefício de terceiro (objeto

\footnotetext{
${ }^{21}$ COSTA E SOUSA, Daniela. Técnicas de reprodução assistida para tratamento da infertilidade. 2016. Dissertação (Mestrado) - Faculdade de Ciências da Universidade do Porto em Biologia Celular e Molecular, Porto, 2016. p. 80. Disponível em: https://repositorio-aberto.up.pt/ bitstream/10216/90939/2/176252.pdf.

${ }^{22}$ OLMOS, Paulo Eduardo. Quando a cegonha não vem: os recursos da medicina moderna para vencer a infertilidade. São Paulo: Carrenho Editorial, 2003.
} 
de estudo neste artigo) ou para a prática da seleção por aperfeiçoamento, ou seja, com fulcro na busca da perfeição da espécie à luz de critérios como capacidades e características físicas ${ }^{23}$.

Os diagnósticos cromossômicos e moleculares, também chamados de biópsia embrionária, visam a avaliar a viabilidade e as condições de saúde do embrião fecundado extracorporeamente ${ }^{24}$. O procedimento se concretiza por meio da biópsia e

análisis in vitro de un corpúsculo polar seguido a un processo de fertilización in vitro, o de un blastômero, de un blastocisto, con el objetivo de prevenir transtornos genéticos en parejas con riesgo de tener uma descendencia afectada por una enfermedad genética ${ }^{25}$.

Em práticas passadas, o diagnóstico antes da implantação permitia apenas a verificação da aptidão do embrião para a gestação, ou seja, a avaliação normal do desenvolvimento embrionário. Porém, a evolução da técnica já possibilita a verificação de algumas informações genéticas, com o objetivo de identificar doenças que futuramente possam se desenvolver ${ }^{26}$, além de propiciar a avaliação de compatibilidade necessária em situações de doação.

Notícias em diversas partes do mundo confirmam o uso do diagnóstico e os benefícios alcançados pelos profissionais que aplicaram a técnica. Um casal britânico que havia perdido um filho vítima de um tipo não comum de câncer no cérebro conseguiu ter um segundo filho saudável após passar pela reprodução assistida, usando o recurso do diagnóstico para seleção de embriões ${ }^{27}$. A genitora era portadora de um gene que aumenta a predisposição ao câncer, de modo que o procedimento seletivo reduziu, consideravelmente, as chances de o segundo filho ter a doença. A diagnose genética embrionária também possibilitou, em 2011, que uma britânica, que tentou ter filhos durante mais de 10 anos, desse à luz dois bebês gêmeos após se submeter a uma nova técnica de verificação genética de embriões. A técnica, que ficou conhecida como hibridização genômica comparativa, permitiu uma espécie de escaneamento em busca de anormalidades genéticas nos embriões em prol de aumentar as chances de uma gravidez bem-sucedida ${ }^{28}$.

\footnotetext{
${ }^{23}$ MEIRELLES, Ana Thereza. Neoeugenia e reprodução humana artificial: limites éticos e jurídicos. Salvador: Editora Juspodivm, 2014.

${ }^{24}$ TEJADA MíNGUEZ, Maria Isabel. Genética médica y eugenesia. In: ROMEO CASABONA, Carlos Maria. La eugenesia hoy. Bilbao-Granada: Editorial Comares, 1999. p.179.

${ }^{25}$ ABELLÁN, Fernando. Selección genética de embriones: entre la libertad reproductiva y la eugenesia. Granada: Comares, 2007. p.76.

${ }^{26}$ FRIAS, Lincoln. A ética do uso e da seleção de embriões. Florianópolis: Editora UFSC, 2012. p. 13.

${ }^{27}$ MEIRELLES, Ana Thereza. Neoeugenia e reprodução humana artificial: limites éticos e jurídicos, cit.

${ }^{28}$ Id. Ibid.
} 


\section{A seleção genética}

O diagnóstico genético pré-implantacional é um mecanismo de concretização da seleção genética, que pode ser realizada com objetivos distintos, seja para a implantação de embriões saudáveis nos processos assistidos de reprodução, seja para avaliação das condições de compatibilidade com eventual receptor de transplante.

O tratamento jurídico da seleção genética no Brasil é representado por uma nítida lacuna, já que a lei que versa sobre manipulações genéticas em seres humanos não emitiu regulação clara sobre seus diversos aspectos, tampouco esclareceu a medida de permissão no que tange às possibilidades que podem envolver a prática do ato seletivo. A Lei n. $11.105 / 2005^{29}$ proibiu a engenharia genética em células reprodutivas e a clonagem, mas não conferiu posição sobre a seleção genética.

A lacuna na ordem jurídica foi parcialmente ocupada por recomendação de normativa do Conselho Federal de Medicina (CFM), cuja Resolução n. 2.168/2017 30 determina que as técnicas de reprodução assistida

também podem ser utilizadas para tipagem do sistema HLA do embrião, no intuito de selecionar embriões HLA-compatíveis com algum irmão já afetado pela doença e cujo tratamento efetivo seja o transplante de células-tronco, de acordo com a legislação vigente.

Cumpre esclarecer quais são as possibilidades seletivas que englobam o uso do diagnóstico genético.

\section{Condutas neoeugênicas}

O uso do diagnóstico em processos assistidos de reprodução com propósito de seleção genética também agrega a possibilidade de praticar condutas não apenas estritamente terapêuticas, mas de natureza eugênica. $O$ conceito atual de eugenia, que ainda evidencia forte carga histórica, passou a abranger realidades novas, contextualizadas por demandas sociais diferentes, benefícios e riscos científicos variados, fatos precursores, conforme propôs Jürgen Habermas, de uma espécie de eugenia liberal, pautada na oferta e na procura, que também pode ser chamada de neoeugenia. Antes, os recursos

\footnotetext{
${ }^{29}$ BRASIL. Lei n. 11.105, de 24 de março de 2005. Regulamenta os incisos II, IV e V do $\S 1^{\circ}$ do art. 225 da Constituição Federal, estabelece normas de segurança e mecanismos de fiscalização de atividades que envolvam organismos geneticamente modificados - OGM e seus derivados, cria o Conselho Nacional de Biossegurança - CNBS, reestrutura a Comissão Técnica Nacional de Biossegurança - CTNBio, dispõe sobre a Política Nacional de Biossegurança - PNB, revoga a Lei n. 8.974, de 5 de janeiro de 1995, e a Medida Provisória n. 2.191-9, de 23 de agosto de 2001, e os arts. $5^{\circ}, 6^{\circ}, 7^{\circ}, 8^{\circ}, 9^{\circ}, 10$ e 16 da Lei n. 10.814, de 15 de dezembro de 2003, e dá outras providências. Disponível em: http://www.planalto.gov.br/ ccivil_03/_Ato2004-2006/2005/Lei/L11105.htm. Acesso em: 18 fev. 2020.

${ }^{30}$ CONSELHO FEDERAL DE MEDICINA - CFM. Resolução n. 2.168/2017. Disponível em: https://sistemas. cfm.org.br/normas/visualizar/resolucoes/BR/2017/2168. Acesso em: 18 fev. 2020.
} 
relacionados às técnicas de reprodução assistida eram voltados à solução dos problemas de esterilidade e infertilidade, mas hoje apresentam possibilidades cada vez maiores de determinar como serão os descendentes futuros no que tange, substancialmente, a suas configurações genéticas. Abriu-se, na verdade, um leque de possibilidades além do cunho terapêutico, culminando na fantasia em torno da obtenção de um filho perfeito ${ }^{31}$.

A seleção genética pode comportar várias condutas que se concretizam a partir de momentos também distintos da vida do ser humano. $\mathrm{O}$ aconselhamento genético, por exemplo, pode ocorrer em diferentes momentos da vida das pessoas e consite em "uma consulta médica cujo tema são os genes individuais ou familiares. Cabe ao médico geneticista ou à equipe de aconselhamento sob sua supervisão informar sobre o significado de determinados genes para a saúde e o bem-estar das pessoas"32. As informações genéticas propiciadas pela realização do diagnóstico genético podem consistir na identificação da probabilidade de manifestação de doenças futuras ou mesmo no estudo das regras de transmissibilidade de características fenotípicas. Sua legitimidade está, justamente, na primeira finalidade: a consecução de análise genética sobre a possibilidade de manifestação de doenças.

O diagnóstico genético-implantacional (em embriões antes da implantação) pode assumir feições distintas, podendo ter finalidade terapêutica, aperfeiçoadora ou de seleção de sexo. A finalidade terapêutica deve ser o único pressuposto admissível para concretização dos diagnósticos em embriões humanos. A justificação para a admissibilidade do aspecto terapêutico advém da busca natural da saúde, ainda que seja pelos genitores no que se refere ao futuro filho, ou, ainda, com justificação terapêutica no que tange ao benefício da doação ${ }^{33}$.

Os diagnósticos com fins de aperfeiçoamento - ou seja, os que se furtam à finalidade terapêutica - podem se concretizar antes da concepção ou antes da implantação. Em ambos os casos, não há justificação que legitime sua prática, já que estão nitidamente centrados em objetivos de cunho segregacionista. O diagnóstico em embriões para seleção de sexo somente pode ser admitido por motivações terapêuticas, conforme a Resolução n. 2.2168/2017 do CFM.

\section{Para benefício terapêutico de terceiro}

O diagnóstico genético pré-implantatório possibilitará também a concretização da seleção de embriões com a finalidade de gerar um indivíduo para beneficiar terapeuticamente outro indivíduo. $\mathrm{O}$ procedimento assistido para benefício terapêutico de terceiro tem o objetivo de garantir a compatibilidade com o receptor.

\footnotetext{
${ }^{31}$ HABERMAS, Jürgen. O futuro da natureza humana. Tradução de Karina Jannini. São Paulo: Martins Fontes, 2010.

${ }^{32}$ GUEDES, Cristiano; DINIZ, Debora. A ética na história do aconselhamento genético: um desafio à educação médica. Rev. bras. educ. med. [online], n. 33, n. 2, p. 248, 2009. Disponível em: http://www.scielo.br/pdf/ rbem/v33n2/12.pdf. https://doi.org/10.1590/S0100-55022009000200012.

${ }^{33}$ MEIRELLES, Ana Thereza. Neoeugenia e reprodução humana artificial: limites éticos e jurídicos, cit.
} 
Muitos registros já noticiados indicam que a programação de um bebê para beneficiar terapeuticamente outra pessoa é motivada por doenças da medula óssea. Uma vez esgotadas as possibilidades de utilização das células do cordão umbilical, pode ser preciso a realização do transplante de medula óssea do nascido para o portador da enfermidade ${ }^{34}$. No entanto, conforme visto anteriormente, sabe-se que outras doenças podem motivar a indicação para o transplante.

A prática passou a ganhar contornos éticos e jurídicos em diferentes países. Os tribunais britânicos entenderam que a Human Fertilization and Embriology Authory (HFEA), entidade responsável por avaliar demandas em torno do processo assistido de fertilização, também poderia autorizar o procedimento para selecionar embriões compatíveis com irmãos gravemente doentes com o objetivo de usar as células do cordão umbilical do recém-nascido, sendo as principais condições: as autorizações serão concedidas a partir da análise de cada caso, conforme os detalhes de cada situação individual; haver comprovação de que não há outra forma de tratamento; as condições de saúde do filho receptor devem ser graves; não se podem modificar os embriões geneticamente para conseguir a compatibilidade ${ }^{35}$.

Dois precedentes, nos Estados Unidos e no Reino Unido, que ganharam notoriedade merecem um rápido detalhamento. Em 2000 no estado do Colorado, nos Estados Unidos, o casal Nash, com ajuda da seleção genética de embriões, concebeu um filho para tentar salvar, com as células do cordão umbilical, a filha Molly, que era portadora de anemia de Fanconi ${ }^{36}$. E em 2002 no Reino Unido, no caso Zain Hashmi, o casal tinha um filho de 4 anos com talassemia que precisava de transplante de medula, o que justificou o apelo ao diagnóstico genético seletivo ${ }^{37}$.

A Comissão Nacional de Reprodução Humana Assistida (CNRHA) da Espanha, sem deixar de identificar objeções ao procedimento, considerou que não havia razões suficientes para impedir, de forma geral, a realização dessa prática. A comissão entendeu que aos pais caberá o compromisso e o cuidado com a criança que nascerá dadas as circunstâncias relatadas. As valorações tanto positivas, admitindo

\footnotetext{
${ }^{34}$ ABELLÁN, Fernando. Aspectos bioéticos y legales del diagnóstico genético preimplantatorio (DPG). Revista de la Escuela de Medicina Legal, Universidade Complutense, Madrid, n. 3, p. 22, sept. 2006. Disponível em: https://webs.ucm.es/centros/cont/descargas/documento18914.pdf.

${ }^{35}$ Id. Ibid., p. 17-18.

36 “Por tanto, necesitaban asegurarse de dos hechos: i) primero, que el bebé no padecería anemia de Fanconi, lo que sería difícil en un embarazo natural, una vez que ambos padres eran portadores del gene; por consiguiente, las posibilidades de que su hijo nazca con el mismo gene eran considerables (25\%); ii) segundo, que el niño sea un donante compatible con Molly. El diagnostico pre-implantacional les permitía detectar um embrión con esos atributos. Al final, Molly se benefició de un transplante de la medula concedida por su hermano y se conoce que goza de buena salud hasta el día de hoy. Molly no ha sido la primera en beneficiarse de la donación de un Hermano expresamente creado para ese efecto. Simplemente, ha sido el primer caso en que el bebé donante se "fabricó" apelando a la biotecnología científica y no, precisamente, em forma puramente aleatória". (RAPOSO, Vera Lúcia. Se busca embrión en buenas condiciones para la aplicación del diagnostico preimplantacional y el bebe-medicamento. 2009. p. 7. Disponivel em: www.saber.ula.ve/bitstream/.../1/articulo5.pdf. Acesso em: 15 mar. 2018).

${ }^{37}$ ABELLÁN, Fernando. Aspectos bioéticos y legales del diagnóstico genético preimplantatorio, cit., p. 21-22.
} 
o procedimento, quanto negativas, destinadas a rechaçá-lo, constituem especulações teóricas, de difícil ou impossível valoração geral, considerando as especificidades de cada caso e as diferentes questões que podem envolver cada $\mathrm{um}^{38}$.

Em pesquisa publicada em 2012, Julia Lozano Martíneza, Ignacio Gómez Pérez y Justo Aznar Lucea ${ }^{39}$ trouxeram dados importantes relativos aos casos de competência da CNRHA espanhola. A comissão havia recebido 67 petições para reprodução de bebês-medicamentos, 25 das quais não estavam bem fundamentadas e não foram avaliadas. Das restantes, a comissão rejeitou nove, conferiu relatório favorável a 19, mas condicionou outros 12 pedidos à apresentação de dados adicionais, resultando em um total de 31 pedidos deferidos.

O diagnóstico genético pré-implantatório para benefício terapêutico de terceiro no Brasil não é disciplinado normativamente, mas já é uma realidade, conforme atesta notícia publicada em 16 de fevereiro de 2012 no jornal Folha de São Paulo: um casal teve uma filha diagnosticada com talassemia major, doença hereditária que compromete a produção de glóbulos vermelhos ${ }^{40}$.

A seleção buscou embriões que não tivessem a talassemia major e fossem compatíveis para doar células-tronco em um transplante. [...] Os pais são portadores da talassemia --não têm a forma grave da doença. Eles queriam outro filho e procuraram médicos para evitar o nascimento de mais uma criança doente: quando os dois pais têm o gene da talassemia, a chance de gerarem um filho com a forma grave da doença é de $25 \%$. [...] O primeiro passo do tratamento foi a estimulação ovariana, para que a mãe produzisse óvulos a serem fertilizados. Na primeira tentativa, todos os embriões formados tinham a doença. Na segunda, foram formados dez. Dois deles tinham as características desejadas: eram livres da doença ou só portadores do gene e eram compatíveis com a filha para a realização do transplante. O geneticista Ciro Martinhago foi o responsável por criar o método de seleção dos embriões. Ele explica que a escolha para a implantação de embriões livres de doenças genéticas já era feita. A novidade foi a compatibilidade para transplante. No momento do nascimento, células-tronco de seu cordão umbilical foram selecionadas e, depois, congeladas. Um transplante dessas células [...] vai repovoar a medula óssea e fazer com que ela produza glóbulos vermelhos normais. Segundo o hematologista Vanderson Rocha, do

\footnotetext{
${ }^{38} / d$. Ibid., p. 21-23.

${ }^{39}$ LOZANO MARTÍNEZA, Julia; GÓMEZ PERÉZ, Ignacio; AZNAR LUCEA, Justo. ¿És necesaria la producción de bebés-medicamento? Therapeía: estudios y propuestas en ciencias de la salud, v. 4, p. 13-25, jul. 2012. Disponivel em: https://dialnet.unirioja.es/descarga/articulo/4426240.pdf.

${ }^{40}$ BEBÊ gerado após seleção genética vai ajudar tratamento da irmã. Folha de S. Paulo, São Paulo, 16 fev. 2012. Disponivel em: www1.folha.uol.com.br/equilibrioesaude/1049568-bebe-gerado-apos-selecaogenetica-vai-ajudar-tratamento-da-irma.shtml. Acesso em: 22 abr. 2018.
} 
Hospital Sírio-Libanês, onde o transplante deverá ser realizado, o procedimento trará uma chance de até $90 \%$ de sobrevida livre da doença para a menina ${ }^{41}$.

O primeiro bebê nascido na Espanha com propósito terapêutico foi motivado para superar a beta-talassemia maior, enfermidade hereditária que ocasiona uma espécie grave de anemia e demanda transfusões frequentes. À época, calculou-se que a probabilidade de êxito era de $70 \%$ a $90 \%$. Os pais optaram pela fecundação in vitro para que o diagnóstico genético pré-implantacional pudesse propiciar idêntico perfil de histocompatibilidade. As evidências posteriores caminharam para a conclusão de que as reais taxas de êxito da técnica em geral - que vai desde a seleção genética até o nascimento do bebê doador - são de apenas 19\%. Nos casos de beta-talassemia e síndrome de Fanconi, as taxas são boas, considerando a natureza e as características das doenças. Nem sempre a técnica poderá ser aplicada a enfermidade do tipo leucemia por questões ligadas ao tempo, sendo preferível tentar um doador já vivo, e também pelo fato de não existir a necessidade de que as células do doador sejam exatamente iguais às do receptor $^{42}$.

O recurso da seleção genética para concepção de um bebê doador compreende indicações restritas, já que demanda a consideração de fatores concretos relacionados essencialmente às condições da doença do receptor, não sendo um procedimento de simples realização. Isso requer da equipe médica uma avaliação razoável e sistêmica, já que envolve diferentes segmentos da medicina: avaliações hematológica, genética e gineco-obstétrica.

\section{0 bebê doador: justificação terapêutica e direitos fundamentais}

A Lei n. 9.434/19973, recentemente regulamentada pelo Decreto $n$. 9.175/2017, disciplina a transplantação de órgãos e tecidos, seja sob a forma post mortem ou entre pessoas vivas. Conforme o artigo $9^{\circ}$ da lei, a transplantação entre vivos naturalmente demanda a manifestação do consentimento do doador, o que exige a condição da capacidade. O Estado ou qualquer outra pessoa jamais pode apropriar-se do corpo de alguém para executar a retirada de órgãos e tecidos sem que seu titular se manifeste.

\footnotetext{
${ }^{41}$ BEBÊ gerado após seleção genética vai ajudar tratamento da irmã, cit.

${ }^{42} \mathrm{COLLAZO} \mathrm{CHAO}$, Eliseo. Problemas éticos en la selección de embriones con finalidad terapéutica. Cuadernos de Bioética, Asociación Española de Bioética y Ética, v. 21, n. 2, p. 234-235, mayo./ago. 2010. Disponível em: https://www.redalyc.org/articulo.oa?id=87515708006.

${ }^{43}$ BRASIL. Lei n. 9.434, de 4 de fevereiro de 1997. Dispões sobre a transplantação de órgãos e tecidos Disponível em: <http://www.planalto.gov.br/ccivil_03/leis/I9434.htm>. Acesso em: 18 jan. 2018.
} 
A Lei n. 9.434/1997 restringe a possibilidade de doação entre vivos a órgãos duplos, partes de órgãos, tecidos ou partes do corpo, correspondendo a uma necessidade terapêutica comprovada indispensável à pessoa receptora

cuja retirada não impeça o organismo do doador de continuar vivendo sem risco para a sua integridade e não represente grave comprometimento de suas aptidões vitais e saúde mental e não cause mutilação ou deformação inaceitável.

Também prevê a possibilidade de que o indivíduo juridicamente incapaz, com compatibilidade imunológica comprovada, possa fazer doação nos casos de transplante de medula óssea, condicionada ao consentimento de ambos os pais ou de seus responsáveis legais, além da exigência de que o ato não ofereça risco a sua saúde. Acrescenta, ainda, que "é vedado à gestante dispor de tecidos, órgãos ou partes de seu corpo vivo, exceto quando se tratar de doação de tecido para ser utilizado em transplante de medula óssea e o ato não oferecer risco à sua saúde ou ao feto" (Lei n. 9.434/1997).

Depreende-se do conteúdo legal a expressa autorização da transplantação para casos ligados à medula óssea envolvendo juridicamente incapazes, mas, como sabido, a lei carece de atualização no que tange a procedimentos relacionados a transplantações motivadas por outras doenças sanguíneas.

O tratamento normativo conferido ao tema não evidencia suficiente clareza, posto estar em descompasso com o atual estágio das possibilidades relacionadas à seleção genética e ao conjunto de doenças que podem justificar a realização de um transplante. Além disso, é irrefutável que sejam discutidos mecanismos de aferição de pressupostos éticos que envolvam a prática da seleção. Nem a lei nem a resolução do CFM trataram de disciplinar como a situação deve ser conduzida do ponto de vista prático, como já ocorre nos países onde há comissões especializadas para discutir com técnica, brevidade e ética os pontos concernentes.

O primeiro entrave moral e ético que pode rechaçar a admissibilidade do diagnóstico genético embrionário para benefício terapêutico de outrem é traduzido pela interpretação do imperativo categórico kantiano: considerar o ser humano sempre como um fim em si mesmo, e nunca como um meio. Assim, sabe-se que a sustentação de um projeto parental onde alguém seja concebido para servir a outro é de extrema delicadeza para a ética.

Acrescente-se que a análise da legitimidade moral do procedimento tem argumento assentado na ideia de dignidade da pessoa humana, imperativo irrefutável quando se pensa em qualquer situação que venha tornar tangíveis a integridade e a existência de qualquer ser humano. A dignidade como um valor a ser perseguido é capaz de desautorizar condutas que instrumentalizem pessoas ou reduzam sua condição ontológica. A existência de alguém não pode ser contingenciada por uma realidade que a estigmatize como o medicamento que servirá a outrem. 
A questão, então, pode ser reconduzida para a necessidade de avaliar como esse futuro indivíduo será concebido no seio familiar, ou seja, se a medida de sua programação genética influencia na percepção de sua existência autonôma, carecedora de todas as proteções destinadas a quaisquer seres humanos. $\mathrm{Na}$ verdade, a situação deve ser ponderada a partir da análise do real interesse dos genitores: a concepção de um filho não pode ser exclusivamente conduzida pelo desejo de salvar outro filho, posto que, antes de tal propósito, trata-se de uma nova vida, da vida de uma nova pessoa.

Disso resulta a necessidade de acompanhamento das situações que possam motivar o projeto parental assistido que busca a reprodução de um doador. A autonomia privada, base fundamentadora das relações contratuais, não pode ser o único elemento incidente sem que outros fatores sejam observados. Na França, tais situações devem ser levadas aos comitês especializados, que analisarão as bases que fundamentam o desejo dos genitores na concepção de um novo filho por meio da prestação de um aconselhamento genético adequado. Por sua vez, o aconselhamento incluirá informações como a possibilidade de que nenhum embrião obtido seja compatível com o irmão enfermo e a perspectiva de uma vinculação futura e forçada entre os irmãos (encadeamento terapêutico) - já que, uma vez admitida a utilização das células do cordão umbilical, possivelmente será preciso realizar transplantes de medula óssea, o que vincularia os irmãos de forma física e psicológica, convertendo um deles em uma espécie de reservatório vivo e permanente do outro $^{44}$. No mesmo sentido, a CNRHA da Espanha também admite a possibilidade de que o diagnóstico seja usado com tal finalidade, desde que acuradas as questões que implicam o uso do recurso de forma individual, a partir das especificidades de cada casal envolvido ${ }^{45}$.

Nesse sentido, é como pensam Rocío Deza Huamán e Chris Delgado Villena, que afirmam ser necessário a criação de um sistema de prevenção efetivo, que inclua autoridades independentes e imparciais "que sirvan como filtros de la autorización brindada por los padres para la procedencia de la donación de su menor hijo; ya que éstas serán capaces de brindar criterios objetivos para determinar la posible afectación del menor" ${ }^{46}$.

Entre tais autoridades, proseguem afirmando que

deberían encontrarse los médicos reunidos en junta y el juez competente en tanto que ellos esgrimirían sus argumentos científicos $y$

\footnotetext{
${ }^{44}$ FRANCE. Comité Consultatif National d'Ethique pour les Sciences de la vie et de la Santé. Réflexions sur l'extension du diagnostic pré-implantatoire. Disponível em: www.ccneethique.fr/sites/default/files / publications/avis072.pdf. Acesso em: 17 abr. 2018.

${ }^{45}$ ESPAÑA. Comisión Nacional de Reproducción Humana Asistida - CNRHA. Actas mayo 2004. Disponível em: www.cnrha.msssi.gob.es/home.htm. Acesso em: 18 abr. 2018.

${ }^{46}$ DEZA HUAMÁN, Rocío del Milagro; DELGADO VILLENA, Chris Almendra. El "uso" de los bebés medicamento a través de la donación: aspectos ético-jurídicos. Revista de Investigación Jurídica, USAT/IUS, n. 10, p. 1-14, 2015.
} 
legales respecto a si sería conveniente o no proceder con la donación y determinarían el límite de donación permitido para el menor ${ }^{47}$.

Os autores entendem que seria necessário conjugar o conhecimento médico com a perspectiva jurídica, de modo que, somente com a participação de médicos e de um jurista, seria legítima a determinação da possibilidade do projeto parental programado e dos limites das doações a serem permitidas. Nítido perceber que esta é uma questão que pertence antes de tudo à ética, já que envolve o uso de procedimentos legais de reprodução e almeja a submissão de um ser vivo a um protocolo de doação sem a obtenção de seu consentimento.

A doutrina aponta para uma divisão entre os que entendem que a reprodução de um bebê-medicamento pode ser chancelada por argumentos de natureza ética e os que entendem que a ética rechaça a possibilidade de praticar a conduta. Seguindo o primeiro entendimento, os partidários da legitimidade da técnica consideram que ela é uma forma de materializar o princípio da beneficência, justificada pelo "imperativo ético de curar o irmão enfermo" diante da possibilidade de usar esse recurso, e também justificada pelos efeitos que o uso da técnica ocasionará para o doador e para a família ${ }^{48}$. O sentido da beneficência seria alcançado pelo compromisso de realização do bem, por meio de comportamentos altruístas, humanitários e voltados à coletividade.

Analisando moralmente a técnica de seleção genética, Fernando Pinto afirma que, apesar da força persuasiva do argumento de natureza moral,

consideramos que no es un obstáculo insalvable para la moralidad del procedimiento. En efecto, el imperativo categórico kantiano parece estar pensado para un supuesto concreto: que los padres concibieran al hijo exclusivamente para salvar a su hermano enfermo. Se trata de una hipótesis que difícilmente se daría en la práctica clínica. El hecho de aumentar la familia con un fin determinado no minora la importancia de otros valores asociados a la natalidad.

Los argumentos éticos que sustentan el "bebé medicamento" presentan, a nuestro juicio, una mayor solidez que las objeciones. En este sentido, entendemos que la moralidad de este procedimiento se asentaría en las razones que impulsan la acción de los tres actores fundamentales: los médicos, los padres y la sociedad ${ }^{49}$.

\footnotetext{
${ }^{47}$ DEZA HUAMÁN, Rocío del Milagro; DELGADO VILLENA, Chris Almendra. op. cit.

${ }^{48}$ PINTO PALACIOS, Fernando. Nacidos para salvar: un análisis ético-jurídico del "bebé medicamento" 2015. Tese (Doutorado) - Universidad Nacional de Educación a Distancia (España). Facultad de Derecho. Departamento de Filosofía Jurídica - UNED, Madrid, 2015. p. 131. Disponível em: http://e-spacio.uned.es/ fez/eserv/tesisuned:Derecho-Fpinto/PINTO_PALACIOS_Fernando_Tesis.pdf.

${ }^{49}$ Id. Ibid., p. 483-484.
} 
Assim, a motivação para uso da técnica também seria extraída do conteúdo ético, justificando-o a ideia de fazer o bem ao outro, desde que respeitados os limites às condições de saúde do doador. A justificação ética estaria na possibilidade de encarar também a doação sob aspecto da alteridade, a partir de uma motivação de natureza benevolente.

Os argumentos contrários ao projeto parental programado para doação também giram em torno da condição ontológica do embrião humano. A escolha pelo projeto parental dessa forma apontaria uma abordagem em que "o conhecimento de uma programação eugênica do próprio patrimônio hereditário limita a configuração autônoma da vida do indivíduo e mina as relações fundamentalmente simétricas entre pessoas livres e iguais" ${ }^{50}$. Os fundamentos contrários à aceitação das condutas que manipulam os embriões humanos para fins de doação partem da concretização de diagnósticos e seleções genéticas, por compreenderem que, dessa forma, restaria desrespeitado o estatuto moral do embrião humano.

No Brasil, o embrião humano titulariza condição diferente da pessoa dentro da ordem jurídica, considerando o disposto na Lei n. 11.105/2005, que admitiu, como destino dos embriões concebidos in vitro e excedentes à fertilização extracorpórea, a doação para pesquisas científicas. $\mathrm{O}$ art. $5^{\circ} \mathrm{da}$ lei garante a possibilidade de que embriões humanos excedentes sejam destinados à pesquisa científica com células-tronco, condicionada ao consentimento de seus genitores ${ }^{51}$.

Considerando a possibilidade prevista pela lei brasileira, que destitui o embrião humano do status jurídico de pessoa nascida, é possível legitimar a técnica de reprodução humana com vistas à doação em benefício do irmão, desde que respeitadas as ponderações apontadas anteriormente.

\section{Considerações finais}

$\mathrm{O}$ aumento das demandas concernentes à possibilidade de transplantes de natureza hematológica na forma alogência (portanto, carecedores de um doador compatível) representa um desafio ético às comunidades médica e jurídica. Vários aspectos apontam para a necessidade de atualizar resoluções éticas e comandos normativos ordinários, não sem que antes a questão tenha sido adequadamente discutida. É difícil que o Direito consiga de fato promover um acompanhamento paralelo adequado a questões que surgem com velocidade na medicina, mas não por isso deve se furtar a discutir problemas fundamentais.

\footnotetext{
${ }^{50}$ HABERMAS, Jürgen. op. cit., p. 33.

${ }^{51}$ MEIRELLES, Ana Thereza. A proteção do ser humano no direito brasileiro: embrião, nascituro e pessoa e a condição de sujeito de direito. Rio de Janeiro: Lumen Juris, 2016.
} 
É necessária, pois, a regulamentação clara quanto à sistemática da reprodução dos bebês doadores, tendo em vista o respeito à condição ontológica do ser humano e a necessidade de que os limites sejam claramente demarcados. É possível justificar a proposta de um projeto parental assistido para a doação a partir de tais limites, que se conformam embasados na proposta da ética e do argumento da condição moral.

O primeiro passo da regulamentação é o acompanhamento das possibilidades de maneira prática, por meio de comissões especializadas que consigam avaliar as situações a partir das condições específicas de cada caso. A justificativa para a realização da seleção genética com essa finalidade está primordialmente na proposta terapêutica que agrega chance significativa de garantir a continuidade da vida de uma outra pessoa, irmão do indivíduo doador.

A proposta permissiva passa pela avaliação dialógica da consciência dos pais, que devem, por meio de acompanhamento psicológico e aconselhamento genético, esboçar a compreensão a respeito da decisão que desejam tomar. A questão agrega, sim, uma apuração com cunho subjetivo, mas isso se justifica pela delicadeza que o propósito da reprodução agrega.

A justificação terapêutica apela ao princípio bioético da beneficência somente até o momento em que não prejudique terapeuticamente (biológica ou psicologicamente) o ser humano doador. Assim, é necessário aclarar as possibilidades que podem envolver a submissão do doador ao protocolo de doação, tais como retiradas de sangue, possíveis tratamentos e medicamentos e internações necessárias.

\section{Referências}

ABELLÁN, Fernando. Aspectos bioéticos y legales del diagnóstico genético preimplantatorio (DPG). Revista de la Escuela de Medicina Legal, Universidade Complutense, Madrid, n. 3, p. 14-26, sept. 2006. Disponível em: https://webs.ucm.es/centros/cont/descargas/ documento18914.pdf.

ABELLÁN, Fernando. Selección genética de embriones: entre la libertad reproductiva y la eugenesia. Granada: Comares, 2007.

ATTAL, Michel et al. Lenalidomide, Bortezomib, and Dexamethasone with Transplantation for Myeloma. N Engl J Med., n. 376, p.1311-320, Apr. 2017.

BEBÊ gerado após seleção genética vai ajudar tratamento da irmã. Folha de S. Paulo, São Paulo, 16 fev. 2012. Disponível em: www1.folha.uol.com.br/equilibrioesaude/1049568-bebe-g erado-apos-selecao-genetica-vai-ajudar-tratamento-da-irma.shtml. Acesso em: 22 abr. 2018.

BRYANT, A. et al. Myasthenia Gravis treated with autologous hematopoietic stem cell transplantation. Journal of the American Medical Association Neurology, v. 376, n. 6: p. 652-658, Jun. 2016. Disponível em: https://www.nejm.org/doi/pdf/10.1056/NEJMoa16117 50 ?articleTools $=$ true. 
COLLAZO CHAO, Eliseo. Problemas éticos en la selección de embriones con finalidad terapéutica. Cuadernos de Bioética, Asociación Española de Bioética y Ética, v. 21, n. 2, p. 231-242, mayo./ago. 2010. Disponível em: https://www.redalyc.org/articulo.oa?id=87515708006.

COPELAN, Edward A. Hematopoietic stem-cell transplantation. $N$ Engl J Med., n. 354, p. 1813-1826, 2006.

COSTA E SOUSA, Daniela. Técnicas de reprodução assistida para tratamento da infertilidade. 2016. Dissertação (Mestrado) - Faculdade de Ciências da Universidade do Porto em Biologia Celular e Molecular, Porto, 2016. Disponível em: https://repositorio-aberto.up.pt/ bitstream/10216/90939/2/176252.pdf.

DEZA HUAMÁN, Rocío del Milagro; DELGADO VILLENA, Chris Almendra. El "uso" de los bebés medicamento a través de la donación: aspectos ético-jurídicos. Revista de Investigación Jurídica, USAT/IUS, n. 10, p. 1-14, 2015.

ESPAÑA. Comisión Nacional de Reproducción Humana Asistida - CNRHA. Actas mayo 2004. Disponível em: www.cnrha.msssi.gob.es/home.htm. Acesso em: 18 abr. 2018.

FRANCE. Comité Consultatif National d'Ethique pour les Sciences de la vie et de la Santé. Réflexions sur l'extension du diagnostic pré-implantatoire. Disponível em: www.ccneethique. fr/sites/default/files /publications/avis072.pdf. Acesso em: 17 abr. 2018.

FRIAS, Lincoln. A ética do uso e da seleção de embriões. Florianópolis: Editora UFSC, 2012.

GARRAFA, Volnei; CORGOZINHO, Marcelo; GOMES, Jacqueline. Transplantes de medula óssea no Brasil: dimensão bioética. Rev. latinoam. bioetica, Bogotá, v. 12, n. 1, p. 36-45, 2012, ene./jun. 2012. Disponível em: http://www.scielo.org.co/pdf/rlb/v12n1/v12n1a04.pdf.

GRATWOHL, Alois et al. Worldwide Network of Blood and Marrow Transplantation. Hematopoietic stem cell transplantation: a global perspective. Journal of the American Medical Association, v. 303, n. 16, p. 1617-1624, Apr. 2010. https://doi.org/10.1001/jama.2010.491.

GUEDES, Cristiano; DINIZ, Debora. A ética na história do aconselhamento genético: um desafio à educação médica. Rev. bras. educ. med. [online], n. 33, n. 2, p. 247-248, 2009. Disponível em: http://www.scielo.br/pdf/rbem/v33n2/12.pdf. https://doi.org/10.1590/S0100-55022009000200012.

HABERMAS, Jürgen. O futuro da natureza humana. Tradução de Karina Jannini. São Paulo: Martins Fontes, 2010.

HINGORANI, Sangeeta. Renal complications of hematopoietic-cell transplantation. N Engl J Med., v. 374, n. 23, p. 2256-2267, Jun. 2016. https://doi.org/10.1056/NEJMra1404711.

HOFFBRAND, A. Victor; MOSS, Paul A. H. Fundamentos em hematologia. 6. ed. Porto Alegre: Artmed, 2013.

INSTITUTO NACIONAL DE CÂNCER - INCA. Informações sobre transplante de células hematopoiéticas. Disponível em: http://www2.inca.gov.br/wps/wcm/connect/orientacoes/ site/home/informacoes_sobre_doacao_de_medula_ossea. Acesso em: 21 maio 2018. 
INSTITUTO NACIONAL DE CÂNCER - INCA. Tópicos em transplante de células-tronco hematopoiéticas. Rio de Janeiro: Ministério da Saúde, INCA, 2012. Disponível em: http:// bvsms.saude.gov.br/bvs/publicacoes/topicos_transplante_celtronco_hematopoeticas.pdf.

LEUKEMIA \& LYMPHOMA SOCIETY. Blood and marrow stem cell transplantation. Revised 2018. Tampa, FL: Sanofi Genzyme, 2018. https:/www.lls.org/sites/default/files/file_assets/ PS40_BloodMarrow_2018.pdf.

LOZANO MARTÍNEZA, Julia; GÓMEZ PERÉZ, Ignacio; AZNAR LUCEA, Justo. ¿És necesaria la producción de bebés-medicamento? Therapeía: estudios y propuestas en ciencias de la salud, v. 4, p. 13-25, jul. 2012. Disponível em: https://dialnet.unirioja.es/descarga/ articulo/4426240.pdf.

MEIRELLES, Ana Thereza. A proteção do ser humano no direito brasileiro: embrião, nascituro e pessoa e a condição de sujeito de direito. Rio de Janeiro: Lumen Juris, 2016.

MEIRELLES, Ana Thereza. Neoeugenia e reprodução humana artificial: limites éticos e jurídicos. Salvador: Editora Juspodivm, 2014.

MILANO, Filippo et al. Cord-blood transplantation in patients with minimal residual disease. N Engl J Med., n. 375, p. 944-953, 2016. https://doi.org/10.1056/NEJMoa1602074.

OLMOS, Paulo Eduardo. Quando a cegonha não vem: os recursos da medicina moderna para vencer a infertilidade. São Paulo: Carrenho Editorial, 2003.

PAI, Sung-Yun et al. Transplantation outcomes for severe combined immunodeficiency. $N$ Engl J Med., n. 371, p. 434-446, 2014. https://doi.org/10.1056/NEJMoa1401177.

PINTO PALACIOS, Fernando. Nacidos para salvar: un análisis ético-jurídico del "bebé medicamento" 2015. Tese (Doutorado) - Universidad Nacional de Educación a Distancia (España). Facultad de Derecho. Departamento de Filosofía Jurídica - UNED, Madrid, 2015. Disponível em: http://e-spacio.uned.es/fez/eserv/tesisuned:Derecho-Fpinto/PINTO_ PALACIOS_Fernando_Tesis.pdf.

RAPOSO, Vera Lúcia. Se busca embrión en buenas condiciones para la aplicación del diagnostico preimplantacional y el bebe-medicamento. 2009. Disponível em: www.saber.ula. ve/bitstream/.../1/articulo5.pdf. Acesso em: 15 mar. 2018.

SNOWDEN, J. A. et al. Autologous hemopoietic stem cell transplantation in severe rheumatoid arthritis: a report from the EBMT and ABMTR. J Rheumatol. , v. 31, n. 3, p. 482-488, Mar. 2004.

SULLIVAN, Keith M. et al. Myeloablative autologous stem-cell transplantation for severe scleroderma. NEngl J Med., n. 378, p. 35-47, Jan. 2018. https://doi.org/10.1056/NEJMoa1703327.

TEJADA MÍNGUEZ, Maria Isabel. Genética médica y eugenesia. In: ROMEO CASABONA, Carlos Maria. La eugenesia hoy. Bilbao-Granada: Editorial Comares, 1999. p. 153-188.

VOLTARELLI, Júlio C.; PASQUINI, Ricardo; ORTEGA, Euza T. T. Transplante de células-tronco hematopoéticas. São Paulo: Atheneu; 2009. 
Araújo A. T. M., Araújo Filho J. E. O.

Ana Thereza Meireles Araújo - Pós-Doutoranda em Medicina e Saúde pela Faculdade de Medicina da Universidade Federal da Bahia (UFBA); doutorado em Relações Sociais e Novos Direitos pela UFBA; mestrado em Direito Privado e Econômico pela UFBA. Professora da Universidade do Estado da Bahia (UNEB), do Programa de Pós-Graduação em Direito da Universidade Católica do Salvador (UCSal) e da Faculdade Baiana de Direito. Salvador/BA, Brasil.E-mail: anatherezameirelles@gmail.com

José Edson Oliveira Araújo Filho - Pós-Graduando em Saúde Coletiva pelo Instituto de Saúde Coletiva da Universidade federal da Bahia (UFBA); graduação em Medicina pela UFBA. Médico da Estratégia da Saúde da Família em Salvador. Salvador/BA, Brasil. E-mail: joseedsonfilho@gmail.com 